ERR A T UM

Patrik Krebs • Marco Conedera $\cdot$ Marco Pradella •

Damiano Torriani - Markus Felber · Willy Tinner

\title{
Quaternary refugia of the sweet chestnut (Castanea sativa Mill.): an extended palynological approach
}

Published online: 20 August 2004

(C) Springer-Verlag 2004

Electronic supplementary material Supplementary material is available in the online version of this article at http://dx.doi.org/10.1007/s00334-004-0048-5.

\section{Veget Hist Archaeobot (2004) 13:145-160}

The legends of Figs. 3-5 were incorrectly published. The correct texts are printed here:

Fig. 3a,b Chestnut pollen percentages for the profiles based on available data for 9 kyr B.P. a) eastern Mediterranean area, b) western Mediterranean area
Fig. 4a,b Chestnut pollen percentages for the profiles based on available data for 7.5 kyr B.P. a) eastern Mediterranean area, b) western Mediterranean area

Fig. 5a,b Chestnut refugium probability index for each site considered. a) eastern Mediterranean area, b) western Mediterranean area

The correct link to the ESM (electronic supplementary material) of the above article is http://dx.doi.org/10.1007/ s00334-004-0048-5

The online version of the original article can be found at http:// dx.doi.org/10.1007/s00334-004-0041-z

P. Krebs · M. Conedera $(\bullet) \cdot$ M. Pradella $\cdot$ D. Torriani WSL Swiss Federal Institute for Forest,

Snow and Landscape Research,

Sottostazione Sud delle Alpi, PO Box 5,

76504 Bellinzona, Switzerland

e-mail: marco.conedera@wsl.ch

M. Felber

Quaternary Geologist,

PO Box 124, 6834 Morbio Inferiore, Switzerland

W. Tinner

Institute of Plant Sciences,

Altenbergrain 21, 3013 Bern, Switzerland 